\title{
Hemochromatosis, alcoholism and unhealthy dietary fat: a case report
}

Venkatachalam Shobi ${ }^{1,5^{*}}$, Awe Adeseye ${ }^{2,5}$, Ballard Billy $y^{3,5}$ and Kalliny Medhat ${ }^{4,5}$

\begin{abstract}
Background: Hereditary hemochromatosis is an autosomal recessive disorder where the clinical phenotype of skin pigmentation and organ damage occurs only in homozygotes. Simple heterozygotes, that is, just C282Y, typically do not develop iron overload. Here we present a case where a simple heterozygote in combination with alcoholism developed high ferritin and high transferrin saturation levels indicative of iron overload. Though alcoholism alone could explain her presentation, we hypothesize that an inflammatory cocktail of iron and alcohol probably caused our patient to succumb to acute liver failure at a very young age.

Case presentation: A 29-year-old Caucasian woman presented to the hospital with progressively worsening yellowish discoloration of her eyes and skin associated with anorexia, nausea, vomiting, diffuse abdominal discomfort, increasing abdominal girth, dark urine and pale stools for about 2 weeks. Family history was significant for hereditary hemochromatosis. Her father was a simple heterozygote and her grandmother was homozygous for C282Y. Physical examination showed scleral icterus, distended abdomen with hepatomegaly and mild generalized tenderness. Lab test results showed an elevated white blood cell count, ferritin $539 \mathrm{ng} / \mathrm{dL}$, transferrin saturation 58.23\%, elevated liver enzymes, elevated international normalized ratio (INR), low albumin, Alcoholic Liver Disease/Nonalcoholic Fatty Liver Disease (ALD/NAFLD) Index (ANI) of 2.6, suggesting a 93.2\% probability of alcoholic liver disease, and phosphatidyl ethanol level of $537 \mathrm{ng} / \mathrm{ml}$. Genetic testing showed that the patient was heterozygous for human homeostatic iron regulator protein (HFE) C282Y mutation and the normal allele. Computed tomography (CT) of the abdomen revealed hepatomegaly, portal hypertension and generalized anasarca. Magnetic resonance cholangiopancreatography (MRCP) showed negative results for bile duct pathology. Workup for other causes of liver disease was negative. A diagnosis of acute alcoholic hepatitis was made, with Maddrey's discriminant function of $>32$, so prednisolone was started. Her bilirubin and INR continued to increase despite steroids, and the patient unfortunately died.

Conclusion: Our case highlights the importance of considering hemochromatosis in the differential diagnosis of young patients presenting with liver failure, including cases suggestive of alcoholism as the likely etiology. Larger studies are needed to investigate the role of non-iron factors like alcohol and viral hepatitis in the progression of liver disease in simple heterozygotes with hereditary hemochromatosis, given the high prevalence of this mutation in persons of Northern European descent.
\end{abstract}

Keywords: Alcoholism, Unhealthy diet, Hereditary hemochromatosis, Case report

*Correspondence: svenkatachalam@mmc.edu

${ }^{1}$ Internal Medicine, Meharry Medical College, Nashville, USA

Full list of author information is available at the end of the article

\section{Background}

Hereditary hemochromatosis (HH) (Fig. 1) is an autosomal recessive disorder where the clinical phenotype of skin pigmentation and organ damage occurs only in homozygotes; even in homozygotes, the phenotype has a broad spectrum depending on sex and original author(s) and the source, provide a link to the Creative Commons licence, and indicate if changes were made. The images or other third party material in this article are included in the article's Creative Commons licence, unless indicated otherwise in a credit line to the material. If material is not included in the article's Creative Commons licence and your intended use is not permitted by statutory regulation or exceeds the permitted use, you will need to obtain permission directly from the copyright holder. To view a copy of this licence, visit http://creativecommons.org/licenses/by/4.0/. The Creative Commons Public Domain Dedication waiver (http://creativeco mmons.org/publicdomain/zero/1.0/) applies to the data made available in this article, unless otherwise stated in a credit line to the data. 


\section{HFE MUTATIONS ON CHROMOSOME 6}

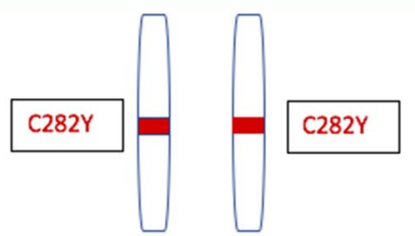

Homozygote

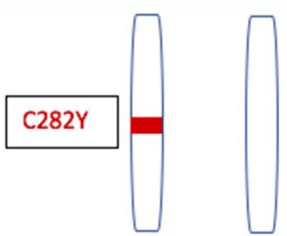

\section{Simple Heterozygote}

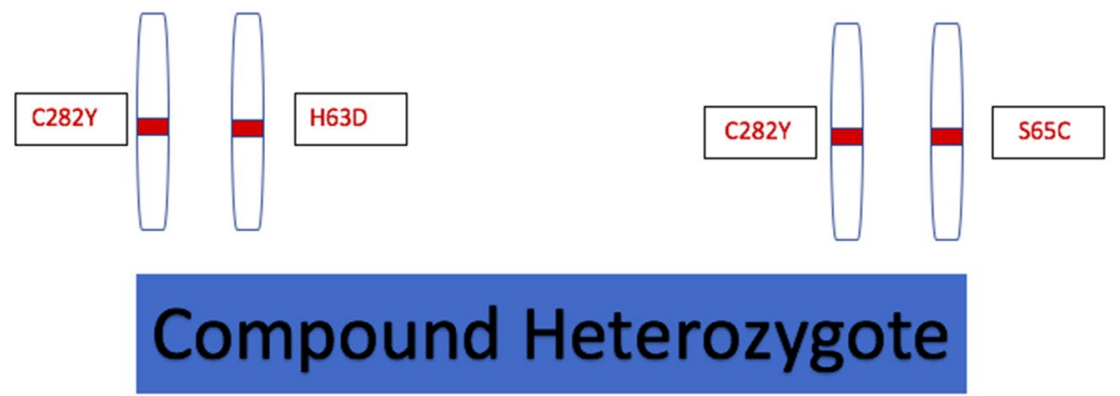

Fig. 1 HFE gene mutations causing Hereditary Hemochromatosis

penetrance which is age-related [1, 2]. With regard to heterozygotes, it is mostly the compound heterozygotes-C282Y and the $\mathrm{H} 63 \mathrm{D}$ or $\mathrm{S} 65 \mathrm{C}$ variant allele-that develop iron overload [3, 4]. Simple heterozygotes - that is, just C282Y-almost never develop iron overload or organ damage [5]. Although the role of non-iron-related factors like alcohol in modulating the iron threshold required to induce liver damage is well known, the strength of their association in each of the $\mathrm{HH}$ phenotypes remains an area that is largely unexplored.

We present a case where a simple heterozygote with alcoholism developed high ferritin and high transferrin saturation indicative of iron overload. This is very rare considering the young age, female sex and the genotype of the patient. The iron overload coupled with probable unhealthy dietary habits in the setting of alcoholism (more fat, less essential nutrients as reported in studies) [6] resulted in an inflammatory cocktail and caused our patient to succumb to acute liver failure at a young age.

\section{Case presentation}

A 29-year-old Caucasian woman presented to the hospital with 2 weeks of progressively worsening yellowish discoloration of her eyes and skin associated with anorexia, nausea, vomiting, diffuse abdominal discomfort, increasing abdominal girth, dark urine and pale stools. Past medical history was significant for prior episodes of hospitalization for acute alcoholic intoxication including an episode a few months prior. Imaging at that time showed hepatic steatosis but no features suggestive of hepatic cirrhosis or portal hypertension. Family history was significant for hereditary hemochromatosis. The patient's father was heterozygous for $\mathrm{C} 282 \mathrm{Y}$ and the paternal grandmother was homozygous for $\mathrm{C} 282 \mathrm{Y}$. The patient reported drinking about 1-2 glasses of wine every day, and denied smoking and illicit drug use. Vitals signs were as follows: pulse rate 94 beats per minute, respiratory rate 20 per minute, blood pressure $112 / 78 \mathrm{mmHg}$, temperature $36.9^{\circ} \mathrm{C}$ and oxygen saturation $100 \%$ on room air. Physical examination showed scleral icterus, distended abdomen with hepatomegaly and mild generalized tenderness.

Laboratory results were as follows (Table 1): white blood cell count $31,600 / \mu \mathrm{L}$, hemoglobin $10.1 \mathrm{~g} / \mathrm{dL}$, 
Table 1 Trend of laboratory values over the course of hospitalization

\begin{tabular}{|c|c|c|c|c|c|}
\hline Laboratory test & Day 1 & Day 8 & Day 16 & Day 23 & Reference range with units \\
\hline WBC & 31.6 & 50.5 & 84 & 48.6 & $4.5-10.010 \times 3 / \mu \mathrm{L}$ \\
\hline $\mathrm{RBC}$ & 3.08 & 2.95 & 2.64 & 2.10 & $4.00-5.0010 \times 6 / \mu \mathrm{L}$ \\
\hline Platelets & 172 & 370 & 309 & 176 & $140-40010 \times / \mu \mathrm{L}$ \\
\hline Hemoglobin & 10.1 & 9.6 & 8.7 & 7.0 & $12.0-16.0 \mathrm{~g} / \mathrm{dL}$ \\
\hline Hematocrit & 27.9 & 29.3 & 27.2 & 20.3 & $39.0-54.0 \%$ \\
\hline MCV & 90.6 & 99.3 & 103 & 96.7 & 80-99fl \\
\hline $\mathrm{MCH}$ & 32.8 & 32.5 & 33 & 33.3 & $27-34 \mathrm{pg}$ \\
\hline $\mathrm{MCHC}$ & 36.2 & 32.8 & 32 & 34.5 & $32-36 \mathrm{~g} / \mathrm{dL}$ \\
\hline RDW & 18.1 & 23.2 & 24.6 & 22.8 & $39.0-54.0 \%$ \\
\hline INR & 1.5 & 2.2 & 1.3 & 1.9 & $0.1-1.4$ \\
\hline BUN & 1 & 5 & 38 & 104 & $7-17 \mathrm{mg} / \mathrm{dL}$ \\
\hline Creatinine & 0.55 & 0.53 & 0.73 & 4.28 & $0.55-1.02 \mathrm{mg} / \mathrm{dL}$ \\
\hline Total bilirubin & 8.7 & 10.3 & 17.4 & 24.7 & $0.2-1.3 \mathrm{mg} / \mathrm{dL}$ \\
\hline Direct bilirubin & 7.4 & & 11.3 & & $0.0-0.2 \mathrm{mg} / \mathrm{dL}$ \\
\hline AST & 90 & 64 & 45 & 71 & $15.00-37.00 \mathrm{U} / \mathrm{L}$ \\
\hline ALT & 30 & 23 & 27 & 12 & $12-78 \mathrm{U} / \mathrm{L}$ \\
\hline ALKP & 420 & 383 & 245 & 168 & $46-116 \mathrm{U} / \mathrm{L}$ \\
\hline
\end{tabular}

WBC white blood cells, $R B C$ red blood cells, $M C V$ cytomegalovirus, $M C H C$ mean corpuscular hemoglobin concentration, $R D W$ red cell distribution width, $B U N$ blood urea nitrogen, $A S T$ aspartate aminotransferase, $A L T$ alanine aminotransferase, $A L K P$ alkaline phosphatase

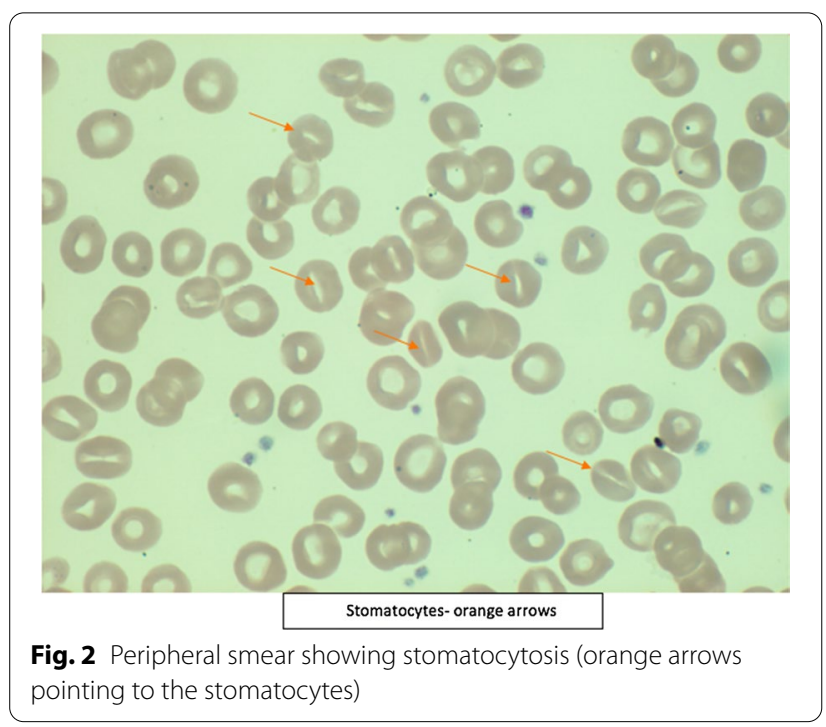

platelets $172 / \mu \mathrm{L}$, ferritin $539 \mathrm{ng} / \mathrm{dL}$, transferrin saturation $58.23 \%$, peripheral blood smear showing stomatocytosis (Fig. 2), total bilirubin $8.7 \mathrm{mg} / \mathrm{dL}$, direct bilirubin $7.4 \mathrm{mg} / \mathrm{dL}$, aspartate aminotransferase (AST) $90 \mathrm{U} / \mathrm{L}$, alanine aminotransferase (ALT) $30 \mathrm{U} / \mathrm{L}$, alkaline phosphatase (ALKP) $420 \mathrm{U} / \mathrm{L}$, prothrombin time (PT) 18.6 seconds, international normalized ratio (INR) 1.5 , blood urea nitrogen $1.0 \mathrm{mg} / \mathrm{dL}$, serum creatinine $0.5 \mathrm{mg} / \mathrm{dL}$, Alcoholic Liver Disease/Nonalcoholic Fatty Liver Disease

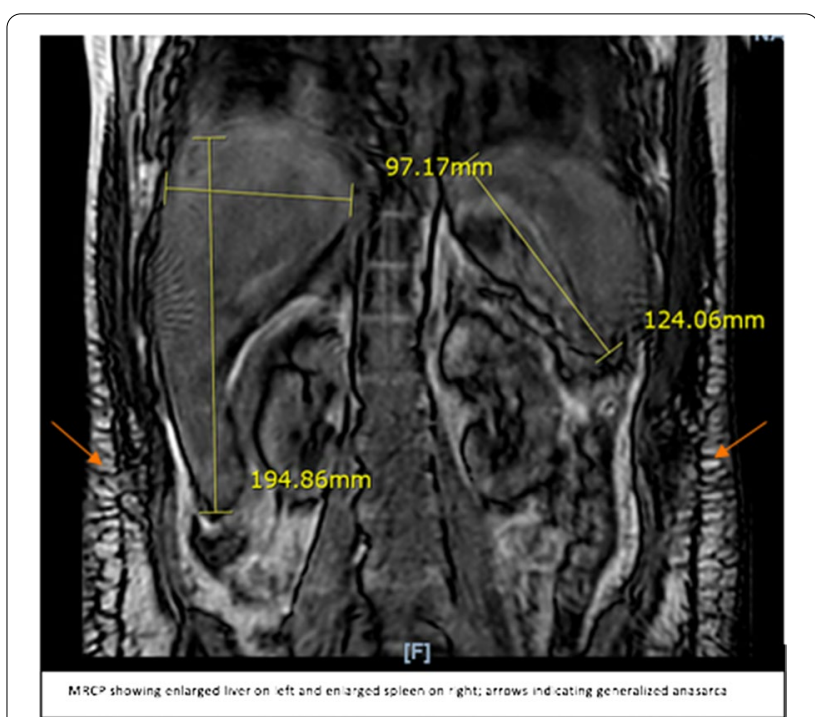

Fig. 3 Magnetic Resonance Cholangiopancreatography (MRCP) showing enlarged liver on the left side of the image (shown using yellow array of lines on the left), enlarged spleen on the right side of the image (shown using yellow array of lines on the right) and generalized anasarca (pointed using orange arrows)

(ALD/NAFLD) Index (ANI) 2.6, suggesting a 93.2\% probability of alcoholic liver disease, and phosphatidyl ethanol level $537 \mathrm{ng} / \mathrm{ml}$ (levels $>20 \mathrm{ng} / \mathrm{ml}$ indicate moderateheavy ethanol consumption). Genetic testing results revealed that the patient was heterozygous for the HFE 
C282Y mutation and the normal allele, as well as negative for H63D and S65C. Imaging showed features suggestive of parenchymal liver disease, portal hypertension and generalized anasarca (Fig. 3). Magnetic resonance cholangiopancreatography (MRCP) was negative for bile duct pathology. Workup for other causes of liver disease including autoimmune hepatitis, Wilson's disease, alpha-1 antitrypsin deficiency, celiac disease, primary biliary cirrhosis (PBC), Epstein-Barr virus (EBV), cytomegalovirus (CMV), viral hepatitis, tick-borne illnesses and leptospirosis all returned negative results. Biopsy of the liver was considered but was held due to the patient's worsening general medical condition.

The patient was diagnosed with acute alcoholic hepatitis, and Gastroenterology was consulted. The patient's Maddrey's discriminant function was 46.4 (a score $>32$ indicates poor prognosis and that the patient might benefit from glucocorticoid therapy), so orally administered prednisolone $40 \mathrm{mg} /$ day was started. Although the patient's total bilirubin (TBIL) and INR initially improved after initiating steroidal therapy, a rebound increase was noted (Table 1), raising concerns for impending liver failure. Also, her creatinine increased from 0.5 to $4 \mathrm{mg} / \mathrm{dL}$. Nephrology was consulted, and a diagnosis of hepatorenal syndrome type 1 was favored. In addition to worsening TBIL, INR and creatinine, the patient developed encephalopathy, succumbed to the disease and died.

\section{Discussion}

In this article we focus on the mechanisms of liver injury from the effects of iron, alcohol and dietary habits, and it may not be surprising to see that some of these mechanisms overlap.

\section{Mechanism of liver injury with iron}

Excess iron in the hepatocytes and Kupffer cells results in the Fenton reaction and reactive oxygen species production. The free radicals induce lipid peroxidation, which damages the mitochondria, resulting in release of cytochrome $\mathrm{c}$ and liver cell apoptosis. Iron overload also stimulates the production of proinflammatory and profibrogenic cytokines including transforming growth factor beta (TGF- $\beta$ ). TGF- $\beta$ leads to the activation of hepatic stellate cells and excess collagen production. Excess collagen and cross-linking coupled with iron inhibit activation of the liver progenitor cells required for the regeneration of liver cells, resulting in fibrosis $[2,7]$.

\section{Mechanism of liver injury with alcohol}

Alcohol is metabolized to acetaldehyde. Acetaldehyde results in the generation of reactive oxygen species, which causes lipid peroxidation and cell membrane and DNA damage. Damaged hepatocytes express antigens which are otherwise hidden from the immune system, resulting in immune stimulation. Chronically heightened immune activity results in immune exhaustion, overwhelming bacterial infection, multi-organ damage and death. Also, chronic alcohol abuse results in overgrowth of gut bacteria, and this along with alcohol-induced leaky gut results in increased delivery of endotoxins to the liver and liver damage [8].

\section{Mechanism of liver injury with non-healthy dietary habits}

Excess dietary fat increases insulin resistance and hyperinsulinemia, which leads to accumulation of fatty acids. Accumulated fatty acids result in the generation of lipotoxic species, hepatocellular oxidant stress and cell death. The dying hepatocytes release signals and express antigens which are otherwise hidden from the immune system. turning on the immunogenic and fibrogenesis cascade [9]. Individual susceptibility to fatty acid-induced oxidant stress depends on other factors including iron overload states such as HFE and alcoholism [2].

Thus, many of the mechanisms of liver injury from iron, alcohol and unhealthy dietary habits overlap (Fig. 4). Although non-HH factors like alcoholism, NAFLD and nonalcoholic steatohepatitis (NASH) are associated with hyperferritinemia from chronic inflammation, the patient's elevated transferrin saturation [(serum iron/total iron binding capacity $) \times 100]$ can only be explained by her HH status. While heavy alcohol consumption alone could cause severe liver damage, we hypothesize that her HFE status and possible unhealthy dietary fat in the setting of alcoholism accelerated the progression of liver disease. Studies have shown that alcoholics consume a higher amount of fatty food and carbohydrates along with lower consumption of vegetables and dairy products, which could have a detrimental effect on health [6].

Clinicians must continually probe for factors like personal or family history of hemochromatosis, dietary habits and alcoholism using different strategies and reformatting questions. This is especially important because early recognition followed by referral to specialized centers for treatment for hereditary hemochromatosis and detoxification would be pivotal in the prognosis of these patients. Our patient persistently denied any unhealthy alcohol use until later in the disease course. This, coupled with her blood alcohol level of $<3$ at admission, very high white blood cell counts, young age and female sex, pointed more towards other differentials like autoimmune hepatitis and infectious 


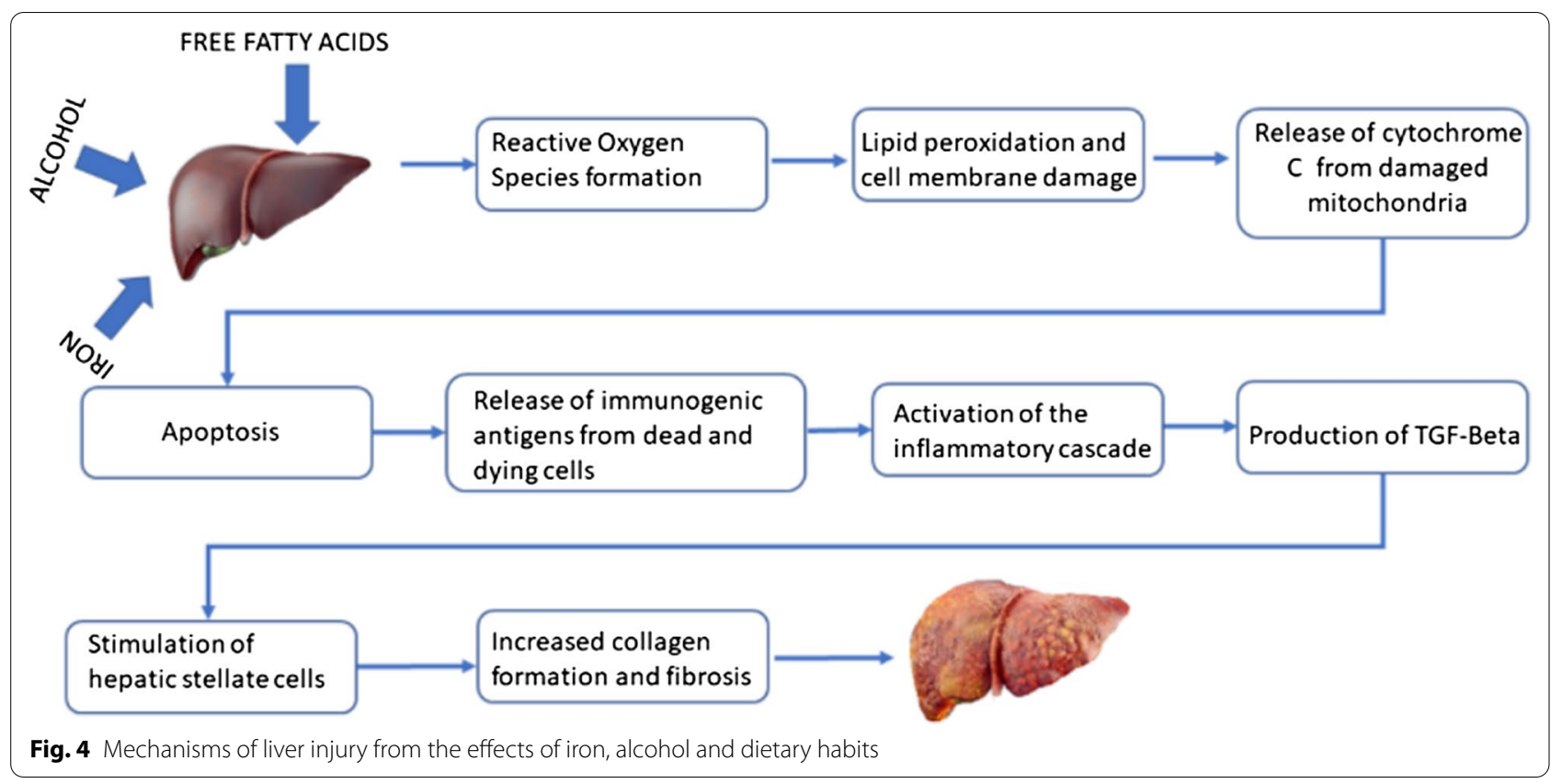

etiologies. Although we were fortunate enough to be redirected towards alcohol as the etiology from reports of stomatocytosis in the peripheral blood, high ANI and very high phosphatidyl ethanol level, the patient unfortunately succumbed to her acute liver failure.

\section{Conclusion}

Considering the high prevalence of $\mathrm{HH}$ and the rising mortality from alcoholic liver disease among young adults $[10,11]$, more studies exploring the role of alcohol in the development of liver damage in simple heterozygotes and vice versa are essential to determine whether all alcoholics have to be screened for hereditary hemochromatosis. This is because more than one factor may often be involved in the pathogenesis and progression of liver dysfunction.

\section{Abbreviations}

WBC: White blood cells; TS: Transferrin saturation [(serum iron/total iron binding capacity) $\times 100]$; ALT: Alanine transaminase; AST: Aspartate transaminase; ALKP: Alkaline phosphatase; PT: Prothrombin time; INR: International normalized ratio; ALD: Alcoholic liver disease; NAFLD: Nonalcoholic fatty liver disease; ANI: ALD/NAFLD Index; CT: Computed tomography; MRCP: Magnetic resonance cholangiopancreatography; HFE: Human homeostatic iron regulator protein; HH: Hereditary hemochromatosis; TGF: Transforming growth factor; TBIL: Total bilirubin; GI: Gastroenterology; NASH: Nonalcoholic steatohepatitis; PBC: Primary biliary cirrhosis.

\section{Acknowledgements}

Not applicable.

\section{Authors' contributions}

SV-first author, performed literature review, prepared the manuscript AA—second author, contributed to figures and images in the manuscript.
BB — pathologist for our case report. MK—-senior author, edited the manuscript. All authors read and approved the final manuscript.

Funding

No funding was received or used for this case report.

\section{Ethics approval and consent to participate}

Nashville General Hospital Research Oversight Committee (ROC) has determined that a case report does not produce generalizable knowledge, nor is it an investigation of an FDA regulated production.

\section{Consent for publication}

Written informed consent was obtained from the patient for publication of this case report and any accompanying images. A copy of the written consent form is available for review by the Editor-in-Chief of this journal.

\section{Availability of data and material}

Our patient's health record is available in our electronic medical record system, and information can be verified if required by the reviewer.

\section{Competing interests}

The authors declare that they have no competing interests.

\section{Author details}

${ }^{1}$ Internal Medicine, Meharry Medical College, Nashville, USA. ${ }^{2}$ Oral and Maxillofacial Surgery, Meharry Medical College, Nashville, USA. ${ }^{3}$ Pathology, Meharry Medical College, Nashville, USA. ${ }^{4}$ Family Medicine, Meharry Medical College, Nashville, USA. ${ }^{5}$ Meharry Medical College, Nashville, USA.

Received: 9 Auqust 2020 Accepted: 30 November 2020 Published online: 17 February 2021

References

1. Allen KJ, et al. Iron-overload-related disease in HFE hereditary hemochromatosis. N Engl J Med. 2008;358(3):221-30.

2. Fujita $\mathrm{N}$, et al. Iron overload is associated with hepatic oxidative damage to DNA in nonalcoholic steatohepatitis. Cancer Epidemiol Biomark Prev. 2009;18(2):424-32. 
3. Bulaj ZJ, et al. Clinical and biochemical abnormalities in people heterozygous for hemochromatosis. N Engl J Med. 1996;335(24):1799-805.

4. Gurrin LC, et al. HFE C282Y/H63D compound heterozygotes are at low risk of hemochromatosis-related morbidity. Hepatology. 2009:50(1):94-101.

5. Zaloumis SG, et al. Natural history of HFE simple heterozygosity for C282Y and H63D: a prospective 12-year study. J Gastroenterol Hepatol. 2015;30(4):719-25.

6. Kesse E, et al. Do eating habits differ according to alcohol consumption? Results of a study of the French cohort of the European Prospective Investigation into Cancer and Nutrition (E3N-EPIC). Am J Clin Nutr. 2001;74(3):322-7.

7. Mehta KJ, Farnaud SJ, Sharp PA. Iron and liver fibrosis: mechanistic and clinical aspects. World J Gastroenterol. 2019;25(5):521-38.
8. Dunn W, Shah VH. Pathogenesis of alcoholic liver disease. Clin Liver Dis. 2016;20(3):445-56.

9. Friedman SL, et al. Mechanisms of NAFLD development and therapeutic strategies. Nat Med. 2018;24(7):908-22.

10. Adams PC. Epidemiology and diagnostic testing for hemochromatosis and iron overload. Int J Lab Hematol. 2015;37(Suppl 1):25-30.

11. Tapper EB, Parikh ND. Mortality due to cirrhosis and liver cancer in the United States, 1999-2016: observational study. BMJ. 2018;362:k2817.

\section{Publisher's Note}

Springer Nature remains neutral with regard to jurisdictional claims in published maps and institutional affiliations.
Ready to submit your research? Choose BMC and benefit from:

- fast, convenient online submission

- thorough peer review by experienced researchers in your field

- rapid publication on acceptance

- support for research data, including large and complex data types

- gold Open Access which fosters wider collaboration and increased citations

- maximum visibility for your research: over $100 \mathrm{M}$ website views per year

At BMC, research is always in progress.

Learn more biomedcentral.com/submissions 